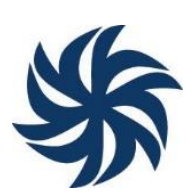

\title{
FEDERALISMO E PODER LEGISLATIVO NA PANDEMIA DE COVID-19: A ATUAÇÃO DA ASSEMBLEIA LEGISLATIVA DO PARANÁ NO ENFRENTAMENTO AO CORONAVÍRUS
}

\author{
FEDERALISM AND LEGISLATIVE BRANCH IN COVID-19: PANDEMIC. \\ PARANÁ'S LEGISLATIVE ASSEMBLY ROLE AGAINST THE \\ CORONAVIRUS
}

\author{
FEDERALISMO Y PODER FEDERATIVO EN LA PANDEMIA: LA \\ ATUACIÓN DEL PARLAMENTO DE LÁ PROVÍNCIA DEL PARANÁ EN \\ CONTRA EL CORONAVÍRUS
}

\author{
Eduardo Soncini Miranda ${ }^{1}$ \\ Roberta Picussa ${ }^{2}$
}

\begin{abstract}
Resumo: O presente artigo tem como objetivo demonstrar a atuação da Assembleia Legislativa do Paraná (Alep) na gestão da crise sanitária imposta pela pandemia de Covid-19. Para tanto, o texto aborda os desafios políticos que agravaram a questão sanitária, entre eles a falta de coordenação entre os entes federados para a elaboração de políticas públicas para o enfrentamento da crise. Por meio de uma pesquisa exploratória sobre as ações desempenhada pela Alep (inovações/adaptações institucionais para deliberações, aprovação de projetos de lei e demais expedientes legislativos, criação de frentes parlamentares, etc.), demonstramos como o poder público em âmbito estadual destacou-se na gestão de crise e evidenciou a maneira cooperada que se deu a relação executivo-legislativo no Paraná. Concluímos que a experiência paranaense foi um exemplo de estratégia promissora para a articulação do sistema federativo brasileiro.
\end{abstract}

Palavra-chave: Poder Legislativo; federalismo; relação executivo-legislativo; pandemia; Covid-19.

Abstract: this paper aims to demonstrate the performance of Parana's Legislative Assembly (ALEP) in managing the health crisis imposed by COVID-19. To this end, it addresses the political challenges that have aggravated sanitary matters, such as the lack of coordination between federated entities regarding the elaboration of public policies to face the crisis. Through an exploratory research on the actions taken by Alep (institutional innovations/adaptations for deliberations, approval of bills and other legislative procedures, creation of parliamentary fronts, etc.) we demonstrate how public power at the state level stood out in the management of the crisis and showed the cooperative way through which the executive-legislative relationship took place in Paraná. We conclude that Paraná's experience was a model of a promising strategy for articulation in the Brazilian federative system.

Keywords: Legislative brench; federalism; executive-legislative relation; pandemic; Covid-19

\footnotetext{
${ }^{1}$ Graduado em Ciências Sociais pela Universidade Federal do Paraná, mestre e doutor em Ciência Política pela mesma instituição.

${ }^{2}$ Graduada em Ciências Sociais pela Universidade Federal do Paraná, mestra em Políticas Públicas e doutoranda em Ciência Política pela mesma instituição.
} 
Resumen: El presente artículo tiene el objetivo de aclarar la actuación del Parlamento de la Provincia de Paraná (Alep) en la administración de la crisis de la pandemia del vírus Covid-19. Así, el artículo trata de los retos políticos que se intensificaron en la cuestión sanitaria, por ejemplo, en la ausencia de coordinación entre entes federales en al tarea de elaboración de políticas públicas para lucha frente a la crisis. Por medio de una investigación sobre las aciones desarrolladas por la Alep (inovaciones/adaptaciones institucionales para decisiones, aprobación de proyectos de leyes y otros trabajos legislativos, creación de grupos parlamentares etc.) pretendemos demostrar como el poder público estadual se destacou apareció en la administración de la crisis y mostró la forma de coordinación en la relación entre ejecutivo-legislativo en la provincia Paraná. Por ende, la experiencia de Paraná fué una estrategia positiva para el enlace del sistema federativo brasileño.

Palabras clave: Poder Legislativo; federativo; relación ejecutivo legislativo; pandemia; Covid-19.

\section{Introdução}

No dia 11 de março de 2020, a Organização Mundial de Saúde (OMS) declarou a pandemia de Covid-19, doença causada pelo novo coronavírus (Sars-Cov-2), com o registro de mais de 115 países com casos de infecção (AGÊNCIA BRASIL, 2020). O cenário alarmante que se desenhava no horizonte fez com que medidas para frear a disseminação do vírus se tornassem prioridade para as autoridades. Na contramão da maioria dos países, o Presidente da República adotou uma postura de menosprezo dos impactos sanitários da pandemia, uma clara preocupação com a economia, a manutenção dos empregos e, vale dizer, uma desconfiança relativa à veracidade das notícias divulgadas pela imprensa e por organismos internacionais como a OMS.

Apesar da postura do Presidente, em fevereiro de 2020, foi publicada lei sobre as medidas para o enfrentamento da emergência de saúde pública decorrente do coronavírus (Lei $\mathrm{n}$. 13.979/2020), a qual permitia que as "autoridades competentes" adotassem medidas como a quarentena, o isolamento social, a realização compulsória de exames médicos, testes laboratoriais, vacinação e outras profiláticas.

Entre as medidas elaboradas pelo governo federal visando o combate à pandemia, destaca-se a tentativa de centralização das ações orientadoras do enfrentamento da pandemia via esfera federal e, nesse sentido, a busca por uma política pública de relaxamento das medidas de isolamento social e o foco na proteção de empregos e da atividade econômica, com destaques às Medidas Provisórias (MPs) n. 926, 927 e 966.

Com o advento das contaminações e dos casos de mortes no Brasil, a população brasileira se viu diante de uma "confusão" entre as orientações oriundas do governo federal, em especial o Ministério da Saúde (MS), que apontava para uma direção, e o presidente apontando e ele mesmo agindo em outra; o apelo feito pelo MS para o isolamento social e o uso de máscaras e as reiteradas atitudes do presidente contrariando-as. Se não bastasse, a "confusão" não era apenas "entre" mas "intra" entes federados. No Mato Grosso, por exemplo, o governador Mauro Mendes (DEM) autorizou a abertura do comércio e o prefeito da capital Cuiabá, Emanuel Pinheiro (MDB), determinou o seu fechamento. 
Em reação às medidas mais enérgicas no combate à pandemia adotadas pelos governos estaduais, o governo federal editou, em março de 2020, a MP n. ${ }^{\circ}$ 926, a qual foi a primeira de uma série de conflitos entre o executivo e o judiciário federal. Ela foi suspensa cautelarmente pelo ministro Marco Aurélio e depois confirmada no plenário do Supremo Tribunal Federal (STF), na Ação Direta de Inconstitucionalidade (ADI) n. 6.341.

No dramático contexto da pandemia, ao apreciar as medidas cautelares requeridas ao STF nas ADIs n. 6.341 e 6.343, o Supremo entendeu que o federalismo brasileiro deveria agir colaborativamente, ou seja, União, Estados-Membros, Distrito Federal e Municípios deveriam preferencialmente planejar e executar políticas públicas conjuntas para o enfrentamento da pandemia. Os ministros deferiram medida cautelar para suspender parcialmente a eficácia de dispositivos das MPs n. 926/2020 e 927/2020. Na eminência de desacordos, entendeu-se que cada ente tem autonomia dentro da sua esfera de atuação. Há, portanto, previsão constitucional para que governadores e prefeitos adotem medidas de contenção da Covid-19 em desacordo com o que propunha o governo federal.

Entre diversas incertezas, sobretudo em relação aos procedimentos mais eficazes e pertinentes a essa nova realidade, a pandemia também trouxe consigo incertezas institucionais. $\mathrm{O}$ Federalismo brasileiro escancarou-se, pois ficou evidente que desde a Constituição de 1988 não segue nem o modelo dual, horizontal/descentralizado típico dos Estados Unidos, nem o modelo cooperativo, vertical/centralizador das Constituições Brasileiras anteriores. Se analisado apenas sob o arranjo constitucional e institucional, ele carece de compreensão, pois o que ficou claro na pandemia é que brechas legais podem explicar muito sobre seu real funcionamento.

Fato é que na querela entre o governo federal e o Poder Judiciário, foram os governos estaduais que tomaram a dianteira nas medidas legais à imposição do isolamento social. O Estado do Paraná, por exemplo, determinou logo no dia 21 de março, por meio do Decreto n. 4.713/2020, a suspensão dos serviços e das atividades não essenciais e que não atendiam às necessidades inadiáveis da população, incluindo aí a iniciativa privada. A Assembleia Legislativa do Estado do Paraná (Alep) também demonstrou agilidade nas medidas para combater o novo coronavírus.

Este artigo tem como objetivo descrever e analisar as medidas tomadas pela Alep no contexto da pandemia da Covid-19, destacando a capacidade de resposta do Legislativo paranaense à gestão de crises sanitárias e o papel por ela desempenhado no contexto da proeminência dos governos estaduais nessa pandemia. Para tanto, serão abordadas: as medidas regimentais que possibilitaram a continuação de seus trabalhos; as legislações aprovadas na Casa para atenuar as consequências da pandemia; as ações de fiscalização do Executivo; a representação das demandas da população; e os recursos cedidos do seu orçamento para enfrentamento da pandemia. 


\section{Revisão da literatura}

As bases políticas do federalismo brasileiro revelam poderes executivos fortes, com legislativos multipartidários, necessitando, portanto, os chefes dos poderes executivos, de ampla capacidade de negociação para formar bases legislativas de apoio às suas agendas políticas.

Se já sabíamos que a nossa Constituição de 1988 indica características cooperativas e forte coordenação federal para o funcionamento do sistema político brasileiro, desde o começo da pandemia no Brasil, foi possível identificar a adoção de medidas de distanciamento social para tentar controlar o avanço da Covid-19 na maioria dos estados e uma verdadeira corrida contra o tempo a fim de ampliar/estruturar os leitos de UTI públicos. "A Federação brasileira ainda tem problemas de fragmentação, sobreposição, competição e fragilidade de cooperação em alguns setores e no plano territorial. Só que, mesmo com esses problemas, ela vinha avançando no reforço da coordenação e cooperação intergovernamentais na provisão das políticas públicas" (ABRUCIO, 2020, p. 663).

Chama a atenção, no entanto, especialmente nesse cenário da pandemia, a posição de negação e ausência de coordenação, papel histórica e constitucionalmente voltado ao governo federal. Apesar de na prática serem os governadores e os prefeitos os maiores executores de políticas públicas específicas no contexto da pandemia, é da União que os indispensáveis recursos financeiros vêm, já que o dinheiro chega a governadores e prefeitos por meio de repasses (RODRIGUES; AZEVEDO, 2020). Importante, portanto, conhecermos os estudos sobre as relações entre entes federados: União, Estados e Municípios (federalismo) e também dentro do Estado (estudos de política subnacional).

Mesmo sendo minoria dentro da literatura especializada, diversos autores se debruçaram à análise subnacional da política brasileira (ANDRADE, 1998; ABRUCIO, 1998; SANTOS, 2007; TOMIO; RICCI, 2018). Abrucio (1998) analisa 15 estados da federação (legislatura 19911994) e expõe o papel coadjuvante e frágil do Poder Legislativo, em especial, as Assembleias Legislativas, frente ao papel protagonista do Poder Executivo, em especial do governador. Isso aconteceria, sobretudo, pela centralização das iniciativas das principais políticas públicas nas mãos do chefe do Poder Executivo. Abrucio lança mão do conceito de "ultrapresidencialismo estadual" para cravar o governo estadual como controlador do "pacto homologatório" que colocaria os deputados estaduais em menor destaque, quase que sobrando a esses últimos apenas uma atuação referendatória, de menor importância política, quase que formal/burocrática. Nessa esteira, há dominância do Executivo sobre o Legislativo no processo decisório estadual, acentuando um desequilíbrio entre ambos no sistema político brasileiro.

Na sequência, Santos (2001) analisa seis estados da federação (legislatura 1995-1998), mostrando o caráter histórico e restrito da obra de Abrucio. No livro, Santos (2001) aponta uma variedade de achados e conclusões sobre os diferentes estados analisados, entre eles: maior 
equilíbrio entre os Poderes Legislativo e Executivo nos estados do Rio de Janeiro e Minas Gerais, o que enfatiza o caráter autônomo das Assembleias locais; grande capacidade governativa dos Executivos no Rio Grande do Sul e Ceará, resultante de maiorias partidárias estáveis, produto de alianças eleitorais. Santos admite a presença do "ultrapresidencialismo" apenas nos estados de São Paulo e Espírito Santo.

Mais recentemente, Tomio e Ricci (2012) apresentam os achados de uma série de pesquisas, temas e autores sobre o federalismo e as relações executivo-legislativas nos estados brasileiros. Destacam principalmente o caráter diverso da lógica subnacional brasileira, especificidades importantes da legislação estadual que dão um padrão próprio e diferente à relação Executivo-Legislativo quando comparamos o nível federal com o estadual no Brasil ${ }^{3}$. Nesse sentido, enaltecem

[...] mas importante é enfatizar o fato de que este sucesso (na taxa de aprovação de propostas oriundas do executivo) não é derivado da fraqueza política da assembleia legislativa, mas sim definido pelo arranjo institucional brasileiro [...] não podemos de imediato concluir que a lógica da relação ExecutivoLegislativo nos estados seja, necessariamente, a de subordinação da Assembleia ao Governador. (RICCI; TOMIO, 2012a, p. 202).

Rogerio Schlegel faz um belo estudo de política comparada internacional e enfatiza as distribuições: 1) "Horizontal" (em uma federação como a brasileira, seria fundamental analisar a relação entre Executivo, Legislativo e Judiciário dentro da mesma esfera de governo); e 2) "Vertical" (fundamental mensurar os recursos de poder entre diferentes níveis de governo para analisar as competências legislativas e administrativas do governo central comparado ao regional ou dessa esfera diante do governo local). Nesse sentido, aplica o Índice de Autoridade Regional (RAI), que demonstra que os estados brasileiros se destacam em termos de autogoverno - a capacidade de a unidade subnacional exercer autoridade sobre o que se passa em seu território.

[...] o retrato que emerge dos Legislativos estaduais é de organismos com potencial para estabelecer relações com o Executivo de caráter mais transacional do que de superioridade hierárquica e que integram um governo regional que representa descentralização moderada da autoridade decisória. (SCHLEGEL; TOMIO; RICCI, 2018, p. 255).

A identificação no Federalismo de um papel amenizador das desigualdades inter e intrarregionais brasileiras já está presente em Souza (2001). Segundo a autora, há uma série de tensões que impactam nosso modelo, as quais estão ligadas ao equilíbrio entre a sustentabilidade financeira/fiscal e a provisão dos serviços públicos em governos subnacionais e passam pela

\footnotetext{
${ }^{3}$ É importante ressaltar que esse não é um ponto pacífico na análise dos autores. Nesse sentido, Tomio e Ricci encontram especificidades em diferentes estados, reforçam os constrangimentos constitucionais referentes ao escopo de atuação legislativa dos deputados estaduais e apresentam evidências de que o sucesso legislativo das propostas oriundas dos parlamentares é alto, mesmo que quase todo restrito à aprovação das chamadas declarações de utilidade pública, como mostraremos também para a Alep nessa pesquisa (Tabela 1).
} 
disparidade de poderes políticos, financeiros e técnicos entre estados e municípios, imersos em um cenário bastante desigual, mas, por vezes, com responsabilidades e prerrogativas de prestação de serviços iguais. As tensões, nesse raciocínio, são mais resultados de conflitos políticos do que do federalismo em si, sendo que seus enfrentamentos dependem, portanto, menos do federalismo e mais do enfrentamento político, além, é claro, da superação dos entraves de políticas econômicas.

A descentralização da educação e da saúde, por exemplo, foi feita sem se avaliar a capacidade administrativa e financeira dos municípios, que varia enormemente. A descentralização não ocorre em um vazio, mas, ao contrário, requer um complexa engenharia político-institucional. (SOUZA, 2001, p. 19).

O tema da saúde pública é o que melhor representa o arranjo institucional brasileiro na prática, na articulação entre política pública e federalismo, ou seja, na cooperação, transferência de recursos, universalização, atendimento e gratuidade. Nesse sentido, a realidade da pandemia no Brasil escancara na prática que o nosso desenho de federação concentra o poder dos recursos financeiros e da legislação na esfera federal, dando grande destaque para estados e municípios na sua implementação, levando em conta suas especificidades locais (TOMIO; ORTOLAN; CAMARGO, 2010; ARRETCHE, 2012).

\begin{abstract}
As análises sobre o processo recente de descentralização apontam, na área social e, em específico, na saúde, a tendência de as variáveis microinstitucionais (poderes locais) terem respondido de forma mais direta pelo (in)sucesso de determinadas políticas, evidenciando um grau de autonomia da gestão local. As respostas às pressões por maior participação dos municípios na área social e em específico na área de saúde, bem como a alta heterogeneidade socioeconômica, política, cultural, demográfica e epidemiológica, propiciaram a formação de modelos singulares de saúde, tanto regionais como locais. Esses modelos são identificados por características particulares, uma vez que as configurações locais dependem de inúmeras variáveis. Neste caso, destacam-se: as formas anteriores ou pretéritas de gestão e organização dos serviços; os arranjos políticos e as formas de expressão dos interesses no plano regional; o tipo de relacionamento estabelecido entre as esferas de poder - executivo, legislativo e judiciário; o grau de associonismo e de capital social criados e desenvolvidos; e, por fim, os perfis de financiamento e gasto local em saúde. (VIANA; LIMA; OLIVEIRA, 2002, p. 499, grifo nosso).
\end{abstract}

$\mathrm{Na}$ área da saúde, dentre uma série de reformas e mudanças que vão desde prerrogativas subnacionais, critérios para alocação e transferência de recursos e a criação de instâncias colegiadas de participação/fiscalização (Conselhos/Comissões Intergestoras), destacamos a criação, oriunda, sobretudo, de movimentos sociais sanitaristas brasileiros, do Sistema Único de Saúde (SUS), como grande marco para esse modelo. O SUS é federativo, descentralizado entre as três esferas de governo (federal/estadual/municipal), universal e gratuito em todo o território nacional e dispõe de amplo controle social. Dentre os desafios à sua eficácia, estão as fragilidades 
de organização frente às desigualdades nacionais, de seu financiamento, da relação entre o setor público e o mercado e de seus processos regulatórios. Não obstante essas fragilidades, algumas soluções são apontadas: organizar redes de serviços regionalizadas e hierarquizadas, com vistas a articular municípios, bem como configurar regiões de saúde e redes de atenção à saúde, com incentivos à colaboração e à coordenação; aprimoramento de instrumentos de coordenação, como as instâncias de pactuação (JACCOUD; VIEIRA, 2018)

[...] superar o caráter formal das normas e das diretrizes instituídas desde a implantação do SUS, promovendo a articulação entre as três esferas de governo para que atuem em um coletivo capaz de consolidar as redes de saúde e de reduzir as desigualdades que marcam a sociedade brasileira (MIRANDA; MENDES; SILVA, 2017, p. 334).

\section{A atuação da Assembleia Legislativa do Paraná na pandemia de Covid-19}

3.1 O processo legislativo via sistema de deliberação remota

A Mesa Diretora da Alep instituiu o Sistema de Deliberação Remota (SDR) no processo legislativo da Casa, por meio da Resolução n. 2, de 23 de março de 2020. A medida foi criada para viabilizar o funcionamento do Plenário e das Comissões excepcionalmente durante a pandemia de Covid-19. A regulamentação não é trivial, pois, segundo Mitozo (2020), embora todas as Assembleias Legislativas do país tenham adotado algum tipo de sistema de deliberação digital nesse período, apenas sete criaram dispositivos legais para garantir a segurança jurídica dessas votações. A Alep destacou-se nesse processo de adaptação para o uso de sistema remoto de deliberação durante a pandemia da Covid-19, em comparação a outras Casas Legislativas:

\footnotetext{
Combinando as características "aprovação de dispositivos legais para regulamentar o trabalho parlamentar remoto", "alto nível de sofisticação de ferramentas" e "alta assiduidade dos parlamentares às sessões remotas", chegase a oito Legislativos que atenderam a todos esses critérios, podendo ser classificados como modelo de gestão digital parlamentar no período de pandemia, a saber: as ALs de Bahia, Ceará, Espírito Santo, Goiás, Mato Grosso, Pernambuco, Paraná e Rio Grande do Norte (MITOZO, 2020, p. 18, grifo nosso).
}

A Resolução que regulamenta o SDR impôs mudanças significativas no trâmite das proposições legislativas iniciadas na Casa. Normalmente, o fluxo processual seria: protocolização da proposição em Plenário, seguindo para a apreciação da Comissão de Constituição e Justiça (CCJ), após, às demais Comissões Permanentes e, então, à Ordem do Dia da Sessão Plenária, na qual seria discutida e votada em três turnos e, aprovada, encaminhada à sanção. A seguir apresentamos, na figura 1, o fluxograma detalhado do trâmite. 
Figura 1 - Fluxograma de tramitação regular das proposições na Alep.

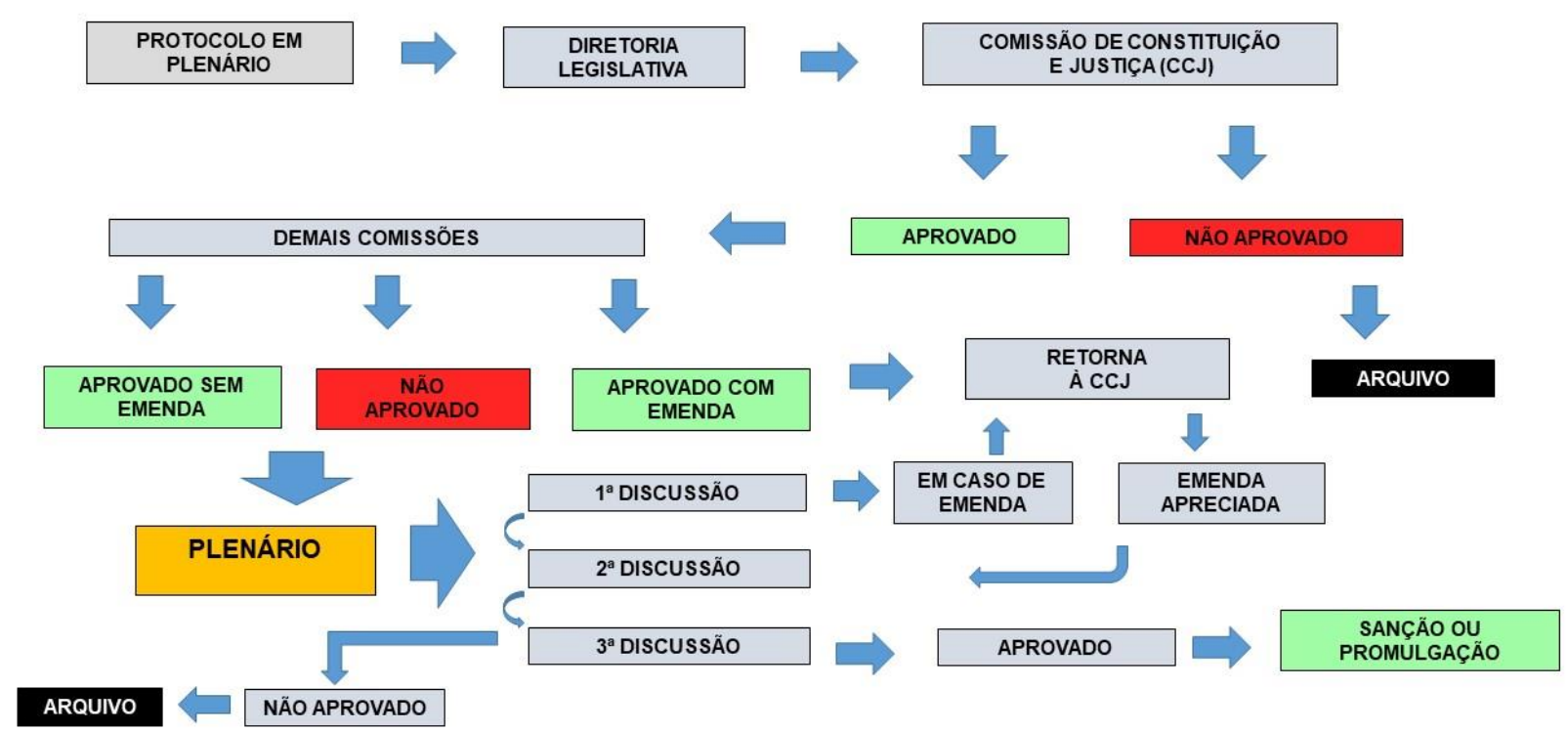

Fonte: Elaborada pelos autores.

Com a nova Resolução, mudanças importantes no fluxo processual foram inseridas. Primeiramente é preciso destacar que as reuniões das Comissões Permanentes foram suspensas, assim, todas as deliberações relativas a uma proposição ocorrem durante a Sessão Plenária. Portanto, ao "acumular" o poder de pauta que antes estava na mão dos diversos presidentes de comissões, as mudanças trouxeram aumento significativo do poder de agenda na figura do Presidente da Alep, Deputado Ademar Traiano (PSDB).

Nesse novo fluxo de deliberação (ver figura 2), as comissões discutem e votam a proposição quando elas já constam na Ordem do Dia da Sessão Plenária. Após aprovado nas comissões, a proposição é então votada em $1 .^{\circ}$ turno, que no Regimento Interno da Alep é

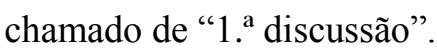


Figura 2 - Fluxograma de tramitação das proposições na Alep sob o sistema de deliberação remota.

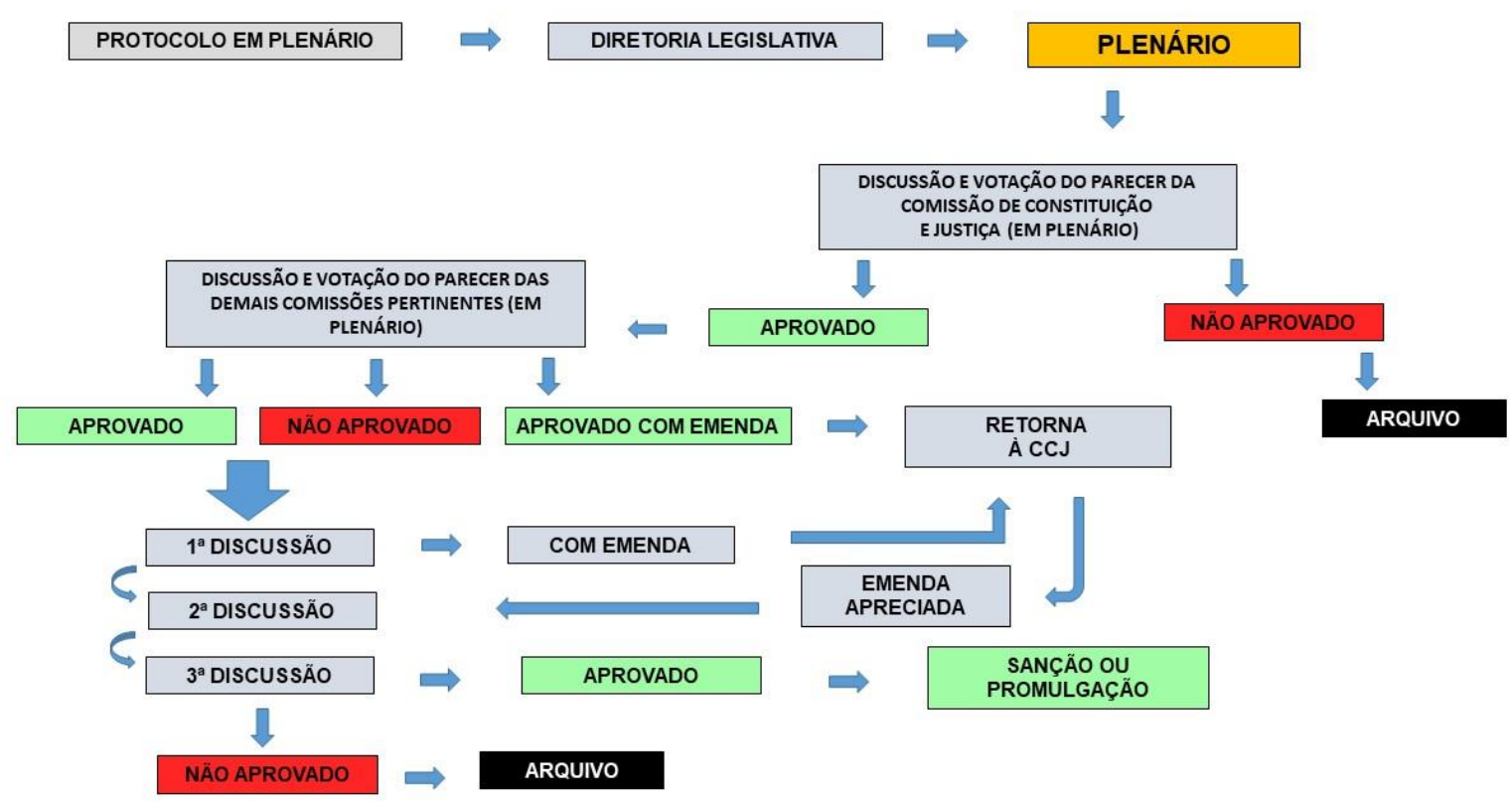

Fonte: Elaborada pelos autores.

Além da redução de instâncias pelas quais as proposições tramitam, destaque-se também a redução do tempo de tramitação. No SDR, quando um projeto entra na Ordem do Dia, todas as comissões emitem pareceres na mesma Sessão, diferentemente do que ocorria quando as reuniões das comissões aconteciam semanalmente e os projetos em geral eram deliberados de acordo com a agenda das reuniões. Além disso, os prazos para deliberação e realização de pedidos de vista eram maiores. Por exemplo, o prazo para o pedido de vista nas comissões foi reduzido de três para um dia no SDR, em regime ordinário, com exceção da Comissão de Constituição e Justiça que mantém o prazo regimental de três dias.

Tais mudanças, se por um lado agilizam a discussão e votação de propostas importantes ao enfrentamento da pandemia de Covid-19, por outro, reduzem significativamente as oportunidades de debate sobre as matérias. Esse aspecto pode ser problemático, pois diferentemente da Câmara dos Deputados, que estipulou a preferência na pauta de votação para matérias relacionais à pandemia (OBSERVATÓRIO DO LEGISLATIVO BRASILEIRO, 2020), a Alep não fez tal distinção na Resolução n. 2/2020, o que significa que proposições de diversos temas podem ser votadas por meio de trâmite reduzido.

O Expediente da Sessão Plenária também foi modificado. No Pequeno Expediente, o tempo de pronunciamento foi reduzido de cinco para quatro minutos para cada orador. No horário das Lideranças Partidárias e dos Blocos Parlamentares, o tempo foi reduzido de dez para cinco 
minutos para cada orador. Além disso, o mesmo orador não pode usar de mais de um horário na mesma Sessão, como ocorria nas sessões de outrora. Como é possível deduzir, essas modificações implicaram em redução significativa das falas em Plenário.

A Alep realizou 111 Sessões Plenárias remotas até 31 de agosto de 2020.

\subsection{Legislações aprovadas para o enfrentamento da Covid-19 na Alep}

A função legislativa da Alep continuou a ser explorada durante a pandemia. Os deputados da Casa aprovaram 147 leis desde que a pandemia começou, até o fim do mês de agosto, 26 delas para combater ou amenizar as consequências da pandemia de Covid-19. As matérias tratam de variados temas ${ }^{4}$, contemplam regras para assegurar condições de segurança sanitária aos cidadãos, como a disponibilização de materiais e a determinação de procedimentos de sanitização em diversos estabelecimentos (Leis n. 20.239/2020 e 20.187/2020), e a obrigatoriedade do uso de máscara (Lei n. 20.189/2020), lei mais antiga e abrangente do que a nacional sobre o mesmo tópico, todas de iniciativa do Poder Legislativo. As legislações abrangem também medidas de proteção social durante esse período, como a proibição de cortes nos serviços de energia elétrica, gás, água e de esgoto durante a pandemia (Lei n. 20.187/2020), e a ampliação e a adequação do Fundo Estadual de Combate à Pobreza (Lei n. 20.171/2020) para o contexto de vulnerabilidade social agravado pela pandemia, permitindo inclusive o uso desse fundo para a viabilização de auxílio emergencial no valor de $\mathrm{R} \$ 50,00$ às famílias economicamente vulneráveis, intitulado “Cartão Comida Boa" (Lei n. 20.172/2020), essas últimas legislações de iniciativa do Poder Executivo.

Além disso, a Alep aprovou leis que contemplaram ações estratégicas para a gestão orçamentária do Estado do Paraná no contexto da pandemia, como a aprovação de crédito especial no valor de $\mathrm{R} \$ 319.300 .850,00$ ao Orçamento Geral do Estado (Lei n. 20.188/2020, de autoria do Executivo), permitindo que valores vigentes do Orçamento que tiveram sua dotação orçamentária cancelada pudessem ser transferidos para ações de saúde direcionadas ao enfretamento da Covid19.

Um grande problema social gerado pela pandemia, o aumento de números de casos de violência conta a mulher, também foi objeto de lei, iniciada e aprovada pela Casa, o dispositivo "Salve Maria", que versa sobre a utilização de tecnologias de comunicação, como o aplicativo WhatsApp, por exemplo, como canal direto com o Poder Público para denúncias de violência doméstica (Lei n. 20.149/2020).

\footnotetext{
${ }^{4}$ A relação completa de leis aprovadas pode ser acessada no sítio eletrônico da Alep, na seção especial dedicada às ações de combate à Covid-19, promovidas pela Casa de Leis: Disponível em: http://www.assembleia.pr.leg.br/comunicacao/covid-19/leis. Acesso em: 31 ago. 2020.
} 
Outra legislação importante promovida pela Alep foram os decretos legislativos de reconhecimento de situação de calamidade pública concedidos a 326 dos 399 municípios paranaenses desde o início da pandemia até o dia 31 de agosto. Esses decretos servem para a dispensa do cumprimento de metas fiscais previstas na Lei de Responsabilidade Fiscal pelos municípios, ficando, dessa maneira, suspensas as restrições decorrentes de descumprimento aos de limites de despesa com pessoal e de dívida consolidada, bem como dispensa do cumprimento de resultados fiscais. Essa medida permite aos gestores municipais fazer as readequações orçamentárias necessárias para atender às demandas emergenciais impostas pela pandemia, sendo esse mais um exemplo de cooperação federativa do Paraná na gestão da crise sanitária.

Tabela 1 - Classificação das leis aprovadas pela Alep pelo Sistema de Deliberação Remota até 31 de agosto de 2020

\begin{tabular}{lcc}
\hline Administração pública & 19 & $(13 \%)$ \\
Concessão de títulos de utilidade pública & 32 & $(22 \%)$ \\
Criação de datas comemorativas/conscientização & 47 & $(32 \%)$ \\
Direito do consumidor & 5 & $(3 \%)$ \\
Meio ambiente e turismo & 2 & $(1 \%)$ \\
Relacionadas à Pandemia de Covid-19 & $\mathbf{2 6}$ & $\mathbf{( 1 8 \% )}$ \\
Outros assuntos & 16 & $(11 \%)$ \\
\hline Total & $\mathbf{1 4 7}$ & $\mathbf{( 1 0 0 \% )}$ \\
\hline
\end{tabular}

Fonte: Elaborada pelos autores.

Das 26 leis aprovadas na Alep para combater ou amenizar as consequências da pandemia de Covid-19, 13 delas são de autoria do Poder Executivo. Isso ocorre porque o escopo de iniciativa legislativa do Poder Executivo é mais amplo do que o do Legislativo. No entanto, é importante frisar que o Legislativo paranaense participa da construção da agenda governamental por meio das emendas feitas aos projetos de iniciativa do governo (TAVARES; MORAES, 2020). Por exemplo, no caso das leis do Poder Executivo citadas acima, os parlamentares fizeram emendas em sete delas (55\% do total). As demais leis aprovadas pela Alep podem ser facilmente encontradas no sítio eletrônico da instituição, pois constam em uma aba pop-up criada especialmente para disponibilizar as ações do Legislativo voltadas ao combate da pandemia de Covid-19. 
Figura 3 - Captura de tela do sítio eletrônico da Alep.

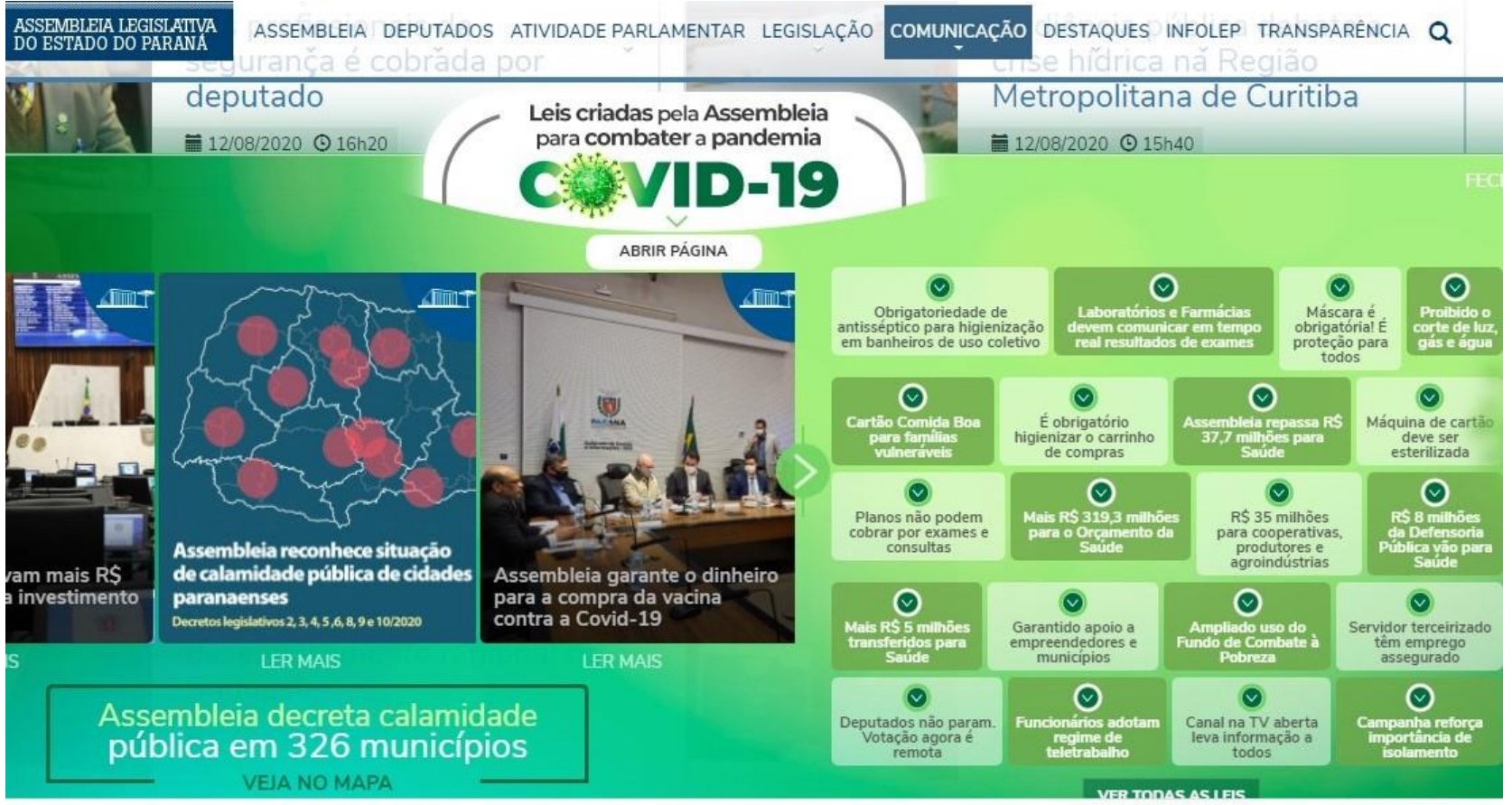

Fonte: Disponível em: http://www.assembleia.pr.leg.br. Acesso em: 31 ago. 2020.

3.3 Relação Executivo-Legislativo entre a Assembleia Legislativa e o Governo do Estado do Paraná.

Nessa pandemia, a Assembleia Legislativa tem realizado ações conjuntas ao governo estadual para promover ações de combate ao coronavírus: o Legislativo paranaense cedeu cerca de R \$ 140 milhões de seu orçamento próprio para o Executivo5. Desse montante, $\mathrm{R}$ \$ 37,7 milhões foram repassados do Fundo Especial de Modernização da Casa para o Fundo Estadual de Saúde (Lei Complementar n. 221/2020), com a finalidade de incrementar a estrutura hospitalar do Estado. Na área da educação, a Casa destinou R \$ 1,5 milhão para a compra de equipamentos pelas universidades estaduais, com a finalidade de serem disponibilizados aos alunos que necessitem de instrumentos de acesso e conexão à internet para poderem assistir às aulas remotamente (GUIMARÃES, 2020).

O maior montante, $\mathrm{R} \$ 100$ milhões, foi destinado à compra de vacinas contra o Sars-Cov2, quando estiverem disponíveis no mercado. O governo estadual, por meio do Instituto de Tecnologia do Paraná (Tecpar), possui parceria de cooperação técnica e científica com a empresa estatal chinesa Sinopharm para a testagem e produção de vacinas, e um memorando de entendimento com o Fundo de Investimento Direto da Rússia visando também uma cooperação

\footnotetext{
${ }^{5}$ Ao todo, R $\$ 200$ milhões foram cedidos do orçamento do Legislativo para o Executivo, mas nem todos os valores foram exclusivos ao combate à pandemia. A Alep devolve anualmente um alto montante de seu orçamento ao Executivo, destinado a políticas públicas distributivas.
} 
técnica com o Instituto Gamaleia para estudos sobre a vacina produzida na Rússia (TECPAR, 2020).

A harmonia entre os poderes Executivo e Legislativo no Paraná não é novidade, mas vem de um longo histórico de sucesso do governador em manter ampla base de apoio no Legislativo (FRANÇA, 2006; MIRANDA, 2013; MELO; TOMIO, 2017) e assim obter aprovação da maioria do Legislativo para implementar suas políticas públicas. O governador Ratinho Junior (PSD) está em seu primeiro ano de mandato, sendo eleito em 2018, no primeiro turno, com 59\% do eleitorado (3.210.712 votos). Seu partido, o PSD, possui a segunda maior bancada da Alep, com sete deputados, a maior bancada pertence ao PSL, com oito parlamentares. Atualmente, a Liderança do Governo da Alep conta com 43 deputados (cerca de $80 \%$ do total de 54 deputados) que se autodeclaram parte da base de apoio ao governador. Esse número pode diminuir em votações ou episódios específicos em que alguns deputados se rebelam contra às orientações da liderança, mas ainda assim a base é robusta. Do restante dos deputados, apenas cinco (9\% do total) compõem a bancada da oposição e o restante (oito deputados, cerca de 15\% do total) se considera independente.

Tabela 2 - Posicionamento dos deputados estaduais paranaenses frente ao governo estadual, no ano de 2020

\begin{tabular}{lcccc}
\hline Nome & Partido & Governo & Oposição & Independente \\
\hline Ademar Traiano (Presidente) & PSDB & & & \\
Alexandre Amaro & PRB & & & \\
Alexandre Curi & PSB & $\mathrm{x}$ & & $\mathrm{x}$ \\
Anibelli Neto & MDB & & & \\
Arilson Chiorato & PT & & & \\
Artagão Junior & PSB & $\mathrm{x}$ & \\
\hline Boca Aberta Junior & PROS & & & \\
Cantora Mara Lima & PSC & $\mathrm{x}$ & & \\
Cobra Repórter & PSD & $\mathrm{x}$ & & \\
Coronel Lee & PSL & $\mathrm{x}$ & & \\
Cristina Silvestri & CDN & $\mathrm{x}$ & & \\
Delegado Fernando & PSL & $\mathrm{x}$ & & \\
Delegado Francischini & PSL & $\mathrm{x}$ & & \\
Delegado Jacovós & PR & $\mathrm{x}$ & \\
Delegado Recalcatti & PSD & $\mathrm{x}$ & \\
Do Carmo & PSL & $\mathrm{x}$ & \\
Douglas Fabrício & CDN & $\mathrm{x}$ & \\
& & & \\
\hline
\end{tabular}




\begin{tabular}{|c|c|c|c|c|}
\hline Dr. Batista & $\mathrm{PMN}$ & $\mathrm{x}$ & & \\
\hline Emerson Bacil & PSL & $\mathrm{x}$ & & \\
\hline Evandro Araújo & PSC & $\mathrm{x}$ & & \\
\hline Francisco Buhrer & PSD & $\mathrm{x}$ & & \\
\hline Galo & PODE & $\mathrm{x}$ & & \\
\hline Gilberto Ribeiro & PP & $\mathrm{x}$ & & \\
\hline Gilson de Souza & PSC & $\mathrm{x}$ & & \\
\hline Goura & PDT & & & $\mathrm{x}$ \\
\hline Homero Marchese & PROS & $\mathrm{x}$ & & \\
\hline Hussein Bakri & PSD & $\mathrm{x}$ & & \\
\hline Jonas Guimarães & PSB & $\mathrm{x}$ & & \\
\hline Luciana Rafagnin & PT & & $\mathrm{x}$ & \\
\hline Luiz Carlos Martins & PP & $\mathrm{x}$ & & \\
\hline Luiz Claudio Romanelli & PSB & $\mathrm{x}$ & & \\
\hline Luiz Fernando Guerra & PSL & & & $\mathrm{x}$ \\
\hline Mabel Canto & PSC & & & $\mathrm{x}$ \\
\hline Marcel Micheletto ${ }^{6}$ & PR & $\mathrm{x}$ & & \\
\hline Marcio Pacheco & PDT & $\mathrm{x}$ & & \\
\hline Maria Victoria & PP & $\mathrm{x}$ & & \\
\hline Mauro Moraes & PSD & $\mathrm{x}$ & & \\
\hline Michele Caputo & PSDB & $\mathrm{x}$ & & \\
\hline Nelson Justus & DEM & $\mathrm{x}$ & & \\
\hline Nelson Luersen & PDT & $\mathrm{x}$ & & \\
\hline Paulo Litro & PSDB & $\mathrm{x}$ & & \\
\hline Plauto Miró & DEM & $\mathrm{x}$ & & \\
\hline Professor Lemos & PT & & $\mathrm{x}$ & \\
\hline Reichembach & PSC & $\mathrm{x}$ & & \\
\hline Requião Filho & MDB & & $\mathrm{x}$ & \\
\hline Ricardo Arruda & PSL & $\mathrm{x}$ & & \\
\hline Rodrigo Estacho & PV & $\mathrm{x}$ & & \\
\hline Soldado Adriano Jose & PV & $\mathrm{x}$ & & \\
\hline Soldado Fruet & PROS & & & $\mathrm{X}$ \\
\hline Subtenente Everton & PSL & $\mathrm{x}$ & & \\
\hline Tadeu Veneri & $\mathrm{PT}$ & & $\mathrm{x}$ & \\
\hline Tercílio Turini & $\mathrm{CDN}$ & $\mathrm{X}$ & & \\
\hline
\end{tabular}

\footnotetext{
${ }^{6}$ Durante o período estudado nesse artigo, o Deputado Marcel Micheletto licenciou-se do cargo para comandar uma
} secretaria estadual. Em seu lugar assumiu o suplente Gugu Bueno (PL). 


\begin{tabular}{lcccc} 
Tiago Amaral & PSB & $\mathrm{x}$ & & \\
Tião Medeiros & PTB & $\mathrm{x}$ & & \\
\hline Total & $\mathbf{1 7}$ & $\mathbf{4 3}$ & $\mathbf{5}$ & $\mathbf{6}$ \\
\hline
\end{tabular}

Fonte: Elaborada pelos autores.

A histórica calmaria e facilidade no que diz respeito à governabilidade entre os poderes Executivo e Legislativo paranaense ganha novos enfoques à medida que no cenário federal há um explícito contexto de tensão e dificuldade do Executivo tanto com os governadores estaduais, quanto com os chefes do Congresso Nacional, como ficou evidenciado no impasse para a compra de vacinas pelo Governo Federal (BRITO, 2020).

Na mesma esteira, presenciamos crises políticas e institucionais nos estados brasileiros, como é o caso do Rio de Janeiro e de Santa Catarina, em que as Assembleias Legislativas formaram maiorias para abrir e depois aprovar os pedidos de impeachment dos seus respectivos governadores (BETIM, 2020). Esses episódios demonstraram que a falta de harmonia entre os Poderes gerou crises políticas que em grande parte sequestraram a agenda do Legislativo, necessária ao enfrentamento da pandemia.

Nesse sentido, frente à ausência de centralização coordenada no governo federal, a antes rotineira e delimitada relação entre os poderes estaduais mostrou-se fundamental até mesmo para o enfrentamento da pandemia no país. Foi sobretudo de esforços subnacionais que algumas das principais medidas de combate à pandemia chegaram à realidade das pessoas.

Além do trabalho conjunto com o Executivo em prol do combate à Covid-19, a Alep também manteve ações de cunho fiscalizatório durante o período de atividades remotas. Desde o início da pandemia, até o dia 31 de agosto, 88 requerimentos com pedidos de informações a órgãos do Executivo foram protocolados. Esse tipo de requerimento tem que ser respondido, sob pena de incorrer em crime de responsabilidade a recusa, de acordo com o art. 55 da Constituição Estadual. As informações solicitadas têm como principal alvo a Secretaria da Saúde e os questionamentos versam sobre diversos temas ${ }^{7}$ : as estratégias da pasta para a gestão de recursos destinados ao combate à pandemia; as informações sobre protocolos de segurança sanitária; a aquisição e distribuição de leitos, respiradores etc.; a política de testagem para detecção da Covid-19; o controle de óbitos e os procedimentos do Instituto Médico Legal para aferição de causa de morte, etc.

\footnotetext{
${ }^{7}$ O procedimento de pesquisa para encontrar os requerimentos consultados para esse artigo consta no anexo 1.
} 
Tabela 3 - Requerimentos de pedidos de informação apresentados pelos deputados estaduais da Alep no período de 11 de março a 31 de agosto 2020

\begin{tabular}{|c|c|c|}
\hline Secretaria de Estado de Saúde & 25 & $28,4 \%$ \\
\hline Casa Civil do Estado & 11 & $12,5 \%$ \\
\hline Secretaria de Estado da Fazenda & 10 & $11,3 \%$ \\
\hline Secretaria de Estado de Segurança Pública & 7 & $7,9 \%$ \\
\hline Demais secretarias e autarquias estaduais ${ }^{8}$ & 35 & $39 \%$ \\
\hline Total & 88 & $100 \%$ \\
\hline
\end{tabular}

Fonte: Elaborada pelos autores.

Outras secretarias também foram demandadas pelos deputados, por exemplo, a Secretaria da Educação foi questionada sobre a paralização das aulas na pandemia e quanto ao plano pedagógico do sistema de educação a distância empregado pela pasta, entre outras informações. A Secretaria da Justiça, Família e Trabalho foi questionada em detalhes quanto às políticas a serem desenvolvidas para atenuar a contaminação por Covid-19 entre as pessoas em situação de rua, moradores de favelas e outras habitações precárias propícias à aglomeração. Ainda, a Secretaria da Fazenda foi questionada quanto à readequação das formas de cobrança de impostos, principalmente em relação ao ICMS e ao IPVA, considerando as dificuldades trazidas pela pandemia.

As políticas públicas do governo estadual também foram fiscalizadas por meio desse expediente, tendo como exemplo o requerimento que questiona inúmeros pontos de uma mensagem governamental enviada à Alep com o objetivo de instituir o "Cartão Social" (Projeto de Lei n. 486/2020), e outro que pediu esclarecimentos ao Executivo quanto a procedimentos que adotados para implementar o programa "Cartão Comida Boa", mas que não constavam no texto da lei aprovada pela Alep.

De acordo com a Diretoria de Assistência ao Plenário da Alep, 175 requerimentos foram protocolados pelos Deputados, tendo como temática a pandemia de coronavírus, dentre os quais estão os pedidos de informações já citados e também os requerimentos de envio de expediente, que se tratam de sugestões ou solicitações formais enviadas aos órgãos governamentais com a finalidade de ampliar e aprimorar as medidas de combate à pandemia. Nesses casos, o Poder

\footnotetext{
8 Os demais números completos são: Secretaria de Desenvolvimento Sustentável e Turismo, 6; Secretaria de Infraestrutura e Logística, 5; Secretaria de Desenvolvimento Urbano, 4; Secretaria da Educação e Esportes, 4; Secretaria da Justiça, Trabalho e Família, 3; Secretaria da Administração e Previdência, 3; Governadoria, 3; Secretaria de Ciência, Tecnologia e Ensino Superior, 1; Secretaria da Agricultura e Abastecimento, 1; Controladoria-Geral do Estado, 1; Companhia de Energia Paranaense, 1; Companhia de Saneamento Paranaense, 1; Procon, 1; Detran, 1. Importante esclarecer que nem todos os pedidos de informação protocolados tinham como temática a pandemia do coronavírus, mas visavam buscar informações também sobre outros aspectos da administração estadual.
} 
Executivo não tem nenhuma implicação jurídica ao deixar de responder, como ocorre nos casos dos pedidos de informação.

Segundo dados da Diretoria Legislativa da Casa, desde que o SDR foi instituído, 2.249 proposições legislativas foram apresentadas: 347 Projetos de Lei; 23 Projetos de Decreto Legislativo; 6 Projetos de Resolução; 2 Propostas de Emenda à Constituição; 1.873 Requerimentos Legislativos; 181 Emendas de Plenário Projetos de Lei, 9 vetos e 8 emendas em Projetos de Lei de autoria dos Poderes Executivo e Judiciário.

3.4 Participação cidadã na Alep: a atuação da Frente Parlamentar do Coronavírus e as audiências públicas on-line

A Alep instituiu a Frente Parlamentar do Coronavírus (FPC), coordenada pelo Deputado Michele Caputo (PSDB), com o objetivo de acompanhar as ações do poder público no enfrentamento à pandemia de Covid-19, bem como ouvir as demandas da sociedade e auxiliar a busca por soluções para esse momento.

Desde a sua criação, em 24 de junho, até o dia 31 de agosto, a FPC reuniu-se on-line 10 vezes, sendo que cada reunião discutiu uma temática específica e trouxe como convidados especialistas nos respectivos temas e representantes dos setores abordados para contribuírem com o debate.

Em virtude das limitações de tempo para pronunciamentos impostas às Sessões Plenárias Remotas, as reuniões da FPC tornaram-se o principal fórum do Legislativo para a discussão mais profunda sobre os problemas que a pandemia causou aos paranaenses. Já foram temas das reuniões: divergência de protocolos médicos para o tratamento da Covid-19; os efeitos da paralisação das aulas presenciais e as condições sanitárias para a retomada; o agravamento da violência contra a mulher na quarentena; medidas para enfrentar a transmissão do vírus no transporte coletivo; retomada das aulas da graduação em modo remoto nas universidades estaduais; aumento de casos de transtorno na saúde mental durante a pandemia, etc.

Uma das consequências do distanciamento social nos trabalhos legislativos foi a limitação da participação da sociedade. As audiências públicas, um dos principais instrumentos para a participação, eram recorrentes na Alep. No ano de 2019, por exemplo, foram realizadas 94 audiências na Casa. No contexto da pandemia, os deputados procuraram realizar audiências públicas on-line. Para isso, fizeram uso do aplicativo Zoom, o mesmo que é empregado para a realização das Sessões Plenárias. Nas audiências, os deputados participantes e as pessoas convidadas para a Mesa de trabalho on-line têm direito à fala. $\mathrm{O}$ público em geral pode participar por meio dos canais de transmissão das audiências, o Youtube e o Facebook, e enviar questões por meio dos comentários nas transmissões desses canais. 
Nesse período de pandemia, entre os meses de março e agosto, 16 audiências públicas foram realizadas na Alep, contemplando os seguintes temas: Lei Maria da Penha - debate das mudanças na Lei; Lei Aldir Blanc e outras medidas emergenciais para o setor cultural; emergência hídrica em Curitiba e região; Esporte no Paraná - medidas de apoio do setor diante da pandemia; efeitos da pandemia no setor do turismo; prestação de contas da Secretaria da Saúde, entre outros.

\section{Conclusões}

O contexto da pandemia trouxe consigo não apenas desafios sanitários, mas também político-institucionais. Num quadro bastante peculiar, os brasileiros viram-se em um cenário de conflitos entre entes federados, em especial devido ao comportamento negacionista, de nada mais nada menos, o presidente da república (ABRUCIO, 2020; LIMA; PEREIRA; MACHADO, 2020). Nesse sentido, diversos dissensos surgiram, tanto em âmbito institucional, quanto na opinião pública, sobre quais as melhores estratégias para o combate à pandemia.

Nosso arranjo institucional estava em xeque, até que o STF deliberou que são concorrentes as ações dos entes federados frente às medidas adotadas no combate à pandemia. Com essa sinalização, o STF consagrou o regime de cooperação entre os entes federativos, assim, Estados, Distrito Federal e Municípios têm competência concorrente para legislar sobre saúde pública (art. 23, II, da Constituição). De posse desse entendimento, o que se viu foram governadores bastante atuantes em medidas para a ampliação do sistema de saúde, de incentivo ao isolamento social, replanejamento/adaptação da educação pública e até mesmo na questão econômica, em que o governo federal é protagonista com o auxílio emergencial (via Caixa Econômica Federal). Alguns estados, como o Paraná, também atuaram com programas análogos, a exemplo do "Cartão Comida Boa". Muitas dessas medidas são de caráter exclusivamente subnacional, ou seja, têm como protagonistas os atores estaduais do processo, vale dizer, governadores e deputados estaduais, tendências que já havia sido apontada por Tomio e Ricci (2012). Procuramos destacar que no caso do Estado do Paraná, o que se viu foi uma atuação cooperada entre as instituições políticas. Ao contrário do que uma parte da literatura especializada já pontuou (ABRUCIO, 1994), o papel dos deputados estaduais e da Alep enquanto instituição foi de protagonismo (SANTOS, 2001). Apesar de o Poder Executivo ter a prerrogativa de iniciativa da maioria das legislações relacionadas ao combate à Covid-19, isso não significa que a Alep tenha um papel apenas homologatório das políticas, uma vez que os parlamentares se destacam tanto na questão de emendamento de Projetos de Lei do Executivo, quanto na questão de participar ativamente da reelaboração do orçamento estadual para potencializar as ações de combate à pandemia de Covid-19 no Estado e, inclusive, direcionar seus próprios recursos para fortalecer os investimentos em saúde. 
Vale ressaltar que nossa pesquisa analisou as 147 leis aprovadas no período crítico da pandemia, excluindo as leis de declaração de utilidade pública e datas comemorativas/conscientização (geralmente são o cotidiano majoritário da produção legal das casas legislativas), sobrando ainda 108 leis gerais, das quais 26 (cerca de 25\%) são de ementas relacionadas à pandemia. Do ponto de vista quantitativo, pode parecer um número pouco significante, mas quando as analisamos sob a perspectiva qualitativa, evidenciamos sua importância. Concluímos, portanto, que do ponto de vista qualitativo, essas 26 leis englobam algumas das mais importantes mudanças no cotidiano prático dos paranaenses frente ao convívio com a pandemia, como exemplo, a obrigatoriedade do uso de máscara (Lei n. 20.189/2020), a proibição de cortes nos serviços de energia elétrica, gás, água e de esgoto durante a pandemia (Lei n. 20.187/2020) e a ampliação e adequação do Fundo Estadual de Combate à Pobreza (Lei n. 20.171/2020), permitindo a viabilização de auxílio emergencial no valor de $\mathrm{R} \$ 50,00$ às famílias economicamente vulneráveis, intitulada "Cartão Comida Boa" (Lei n. 20.172/2020).

O que chamamos de protagonismo não é apenas a produção legal iniciada exclusivamente pelo Legislativo, mas, sobretudo, as maiores possibilidade de atuação que os deputados têm para além da produção de lei. Nesse sentido, destacam-se, por exemplo, a criação da Frente Parlamentar do Coronavírus, as audiências públicas realizadas remotamente e a atuação em vistas a otimizar os recursos do orçamento do Estado para o enfrentamento da pandemia.

Evidenciamos ao longo do artigo que além de uma rápida e otimizada adequação para seu funcionamento, a Alep também cumpriu com suas duas principais funções: 1) Legislar e 2) Fiscalizar. Em relação a seu papel fiscalizatório, a Alep também contribuiu com a promoção de audiências públicas adaptadas ao contexto de isolamento por meio digital e a apresentação de requerimentos com pedidos de informações e outros expedientes enviados aos órgãos governamentais, contendo questionamentos e sugestões para ampliar e aprimorar as medidas de combate à pandemia.

Em suma, por meio do caso paranaense, salientamos o importante papel políticoinstitucional dos níveis subnacionais em tempos de crise e vislumbramos possíveis aprendizados para um aperfeiçoamento do sistema federativo brasileiro no sentido de um federalismo cooperado.

\section{Referências:}

ABRUCIO, Fernando Luiz. Os barões da federação. Lua Nova: revista de cultura e política, São Paulo, n. 33, p. 165-183, 1994.

ABRUCIO, Fernando Luiz et al. Combating COVID-19 under Bolsonaro's federalism: a case of intergovernmental incoordination. Revista de Administração Pública, Rio de Janeiro, v. 54, n. 4, p. 663-677, 2020. 
ANDRADE, Regis de Castro. Processo de governo no município e no estado: uma análise a partir de São Paulo. São Paulo: Edusp, 1998.

ARRETCHE, Marta. Democracia, federalismo e centralização no Brasil. Rio de Janeiro, SciELO-Editora FIOCRUZ, 2012.

AGENCIA BRASIL. Organização Mundial da Saúde declara Pandemia do Coronavírus, Agencia Brasil, publicado em 11 mar. 2020. Disponível em: https://agenciabrasil.ebc.com.br/geral/noticia/2020-03/organizacao-mundial-da-saude-declarapandemia-de-coronavirus. Acesso em: 21 jul. 2020.

BETIM, Felipe. Impeachment vira arma fácil contra governadores neófitos e ex-bolsonaristas do Rio e Santa Catarina. El País, publicado em 23. Set. 2020. Disponível em: https://brasil.elpais.com/brasil/2020-09-24/impeachment-vira-arma-facil-contra-governadoresneofitos-e-ex-bolsonaristas-do-rio-e-santa-catarina.html. Acesso em: 6. nov. 2020.

BRASIL. [Constituição (1988)]. Constituição da República Federativa do Brasil de 1988.

BRASIL. Medida provisória n. ${ }^{\circ}$ 926, de 20 de março de 2020. Altera a Lei n. ${ }^{\circ} 13.979$, de 6 de fevereiro de 2020, para dispor sobre procedimentos para aquisição de bens, serviços e insumos destinados ao enfrentamento da emergência de saúde pública de importância internacional decorrente do coronavirus. Brasil. Disponível em: http://www.planalto.gov.br/ccivil_03/_ato2019-2022/2020/Mpv/mpv926.htm. Acesso em: 9 set. 2020.

BRASIL. Medida provisória n. ${ }^{\circ}$ 927, de 22 de março de 2020. Dispõe sobre as medidas trabalhistas para enfrentamento do estado de calamidade pública reconhecido pelo Decreto Legislativo n. ${ }^{\circ}$ 6, de 20 de março de 2020, e da emergência de saúde pública de importância internacional decorrente do coronavírus (covid-19), e dá outras providências. Brasil. Disponível em: http://www.planalto.gov.br/ccivil_03/_ato2019-2022/2020/mpv/mpv927.htm. Acesso em: 9 set. 2020 .

BRASIL. Medida provisória n. ${ }^{\circ}$ 966, de 13 de maio de 2020. Dispõe sobre a responsabilização de agentes públicos por ação e omissão em atos relacionados com a pandemia da covid-19. Brasil. Disponível em: http://www.planalto.gov.br/ccivil_03/_ato2019-2022/2020/mpv/mpv966.htm. Acesso em: 9 set. 2020.

BRASIL. Lei n. ${ }^{0}$ 13.979, de 6 de fevereiro de 2020. Dispõe sobre as medidas para enfrentamento da emergência de saúde pública de importância internacional decorrente do coronavírus responsável pelo surto de 2019. Brasil. Disponível em: http://www.planalto.gov.br/ccivil_03/_ato2019-2022/2020/lei/113979.htm. Acesso em: 9 set. 2020.

BRASIL. Supremo Tribunal Federal. Medida cautelar na Ação Direta de Inconstitucionalidade 6.341 Distrito Federal. Surgem atendidos os requisitos de urgência e necessidade, no que medida provisória dispõe sobre providências no campo da saúde pública nacional, sem prejuízo da legitimação concorrente dos Estados, do Distrito Federal e dos Municípios. Relator: Min. Marco Aurélio, 24 de março de 2020. Disponível em: http://www.stf.jus.br/arquivo/cms/noticiaNoticiaStf/anexo/ADI6341.pdf. Acesso em: 9 set. 2020. 
BRASIL. Supremo Tribunal Federal. Medida Cautelar na Ação Direta de Inconstitucionalidade 6.343 Distrito Federal. Ante pandemia, há de considerar-se a razoabilidade no trato de providências, evitando-se, tanto quanto possível, disciplinas normativas locais. Relator: Min. Marco Aurélio, 24 de março de 2020. Disponível em: http://www.stf.jus.br/arquivo/cms/noticiaNoticiaStf/anexo/ADI6343decisao.pdf. Acesso em: 9 set. 2020.

BRITO, Ricardo. Governadores pedem ajuda a Maia para Brasil comprar vacina. Terra. Publicado em 3 nov. 2020. Disponível em: https://www.terra.com.br/vida-eestilo/saude/governadores-pedem-ajuda-a-maia-para-brasil-comprar-vacina,659071e04f 422 eeff8f8461b18c57799pqsectq4.html. Acesso em: 6 nov. 2020.

FRANÇA, A. A Assembleia Legislativa do Paraná: organização interna e processo decisório na $14^{a}$ legislatura (1999-2002). Dissertação (Mestrado em Sociologia) - Universidade Federal do Paraná, Curitiba, 2006.

GUIMARÃES, Kharina. Assembleia Legislativa destina R\$ 1,5 milhão para garantir acesso de universitários às aulas remotas. Assembleia Legislativa do Paraná. Publicado em 22 jul. 2020. Disponível em: http://www.assembleia.pr.leg.br/comunicacao/noticias/assembleia-legislativadestina-r-1-5-milhao-para-garantir-acesso-de-universitarios-as. Acesso em: 11 set. 2020.

JACCOUD, Luciana de Barros; VIEIRA, Fabiola Sulpino. Federalismo, integralidade e autonomia no SUS: desvinculação da aplicação de recursos federais e os desafios da coordenação. Brasília: Ipea, 2018.

LIMA, Luciana Dias de; PEREIRA, Adelyne Maria Mendes; MACHADO, Cristiani Vieira. Crise, condicionantes e desafios de coordenação do Estado federativo brasileiro no contexto da COVID-19. Cadernos de Saúde Pública, Rio de Janeiro, v. 36, 2020.

MELO, Fernando Schumack; DE LIMAS TOMIO, Fabrício. Cinquenta anos de produção legislativa paranaense. Revista do Legislativo Paranaense, Curitiba, n. 1, p. 71-94, 2017.

MIRANDA, Eduardo Soncini. Emendas parlamentares e processo legislativo orçamentário, o caso do Paraná (1998-2011). Dissertação (Mestrado em Ciência Política) - Universidade Federal do Paraná, Curitiba, 2013.

MIRANDA, Gabriella Morais Duarte; MENDES, Antonio da Cruz Gouveia; SILVA, Ana Lúcia Andrade da. O desafio da organização do Sistema Único de Saúde universal e resolutivo no pacto federativo brasileiro. Saúde e Sociedade, São Paulo, v. 26, p. 329-335, 2017.

MITOZO, Isabele B. A utilização de sistemas deliberativos remotos pelas Assembleias Legislativas brasileiras durante a pandemia de covid-19: características e prospectos. Revista do Legislativo Paranaense, Curitiba, n. 4, ago. 2020, p. 9-24. Disponível em: http://revista.alep.pr.gov.br/index.php/escolalegislativo/article/view/129. Acesso em: 11 set. 2020.

OBSERVATÓRIO DO LEGISLATIVO BRASILEIRO. O processo legislativo na deliberação remota. Congresso Remoto Boletim 1. Disponível em: https://olb.org.br/wpcontent/uploads/2020/06/Boletim-OLB-Regimento-Remoto_versaofinal.pdf. Acesso em: 15 ago. 2020.

PARANÁ. Constituição Estadual. Constituição do Estado do Paraná de 1988. Disponível em: https://www.legislacao.pr.gov.br/legislacao/exibirAto.do?action=iniciarProcesso\&codAto=9779 \&codItemAto=97592. Acesso em: 15 ago. 2020. 
PARANÁ. Decreto n. ${ }^{\circ} 4317$ de 21 de março de 2020. Dispõe sobre as medidas para a iniciativa privada acerca do enfrentamento da emergência de saúde pública de importância decorrente da COVID-19. Disponível em: https://www.legislacao.pr.gov.br/legislacao/listarAtosAno.do?action=exibir\&codAto=233046\&i ndice $=2 \&$ totalRegistros $=290 \&$ anoSpan $=2020 \&$ anoSelecionado $=2020 \&$ mesSelecionado $=3 \&$ isP aginado=true. Acesso em: 21 jul. 2020.

PARANÁ. Lei n. ${ }^{\circ}$ 20.171, de 7 de abril de 2020. Altera dispositivo da Lei n. ${ }^{\circ} 20.078$, de 18 de dezembro de 2019 e da Lei n. ${ }^{\circ}$ 18.573, de 30 de setembro de 2015. Paraná. Disponível em: https://www.legislacao.pr.gov.br/legislacao/pesquisarAto.do?action=exibir\&codAto=233627\&i ndice $=1 \&$ totalRegistros $=1 \& \mathrm{dt}=11.8 .2020 .23 .43 .50 .700$. Acesso em: 9 set. 2020 .

PARANÁ. Lei n. ${ }^{0} \mathbf{2 0 . 1 8 8}$, de 23 de abril de 2020. Aprova crédito especial, alterando o vigente Orçamento Geral do Estado. Paraná. Disponível em: https://www.legislacao.pr.gov.br/legislacao/pesquisarAto.do?action=exibir\&codAto=234043\&i ndice $=1 \&$ totalRegistros $=1 \& \mathrm{dt}=11.8 .2020 .23 .47 .11 .629$. Acesso em: 9 set. 2020 .

PARANÁ. Lei n. ${ }^{0}$ 20.172, de 7 de abril de 2020. Autoriza a concessão de auxílio emergencial com recursos do Fundo Estadual de Combate à Pobreza do Paraná à pessoa economicamente vulnerabilizada em decorrência da emergência de saúde pública de importância internacional causada pela infecção humana pelo Coronavírus (Covid-19) nas condições que especifica. Paraná. Disponível em: https://www.legislacao.pr.gov.br/legislacao/pesquisarAto.do?action=exibir\&cod Ato $=233646 \&$ indice $=1 \&$ totalRegistros $=1 \& \mathrm{dt}=11.8 .2020 .23 .45 .49 .683$. Acesso em: 9 set. 2020 .

PARANÁ. Lei n. ${ }^{0}$ 20.187, de 22 de abril de 2020. Dispõe sobre diretrizes e medidas de saúde para o enfrentamento e intervenção imediata em situação de emergência em caso de endemias, epidemias e pandemias, inclusive do Coronavírus - Covid-19, no Estado do Paraná, e dá outras providências. Paraná. Disponível em: https://www.legislacao.pr.gov.br/legislacao/pesquisarAto . do ?action $=$ exibir $\&$ codAto $=234042 \&$ indice $=1 \&$ totalRegistros $=1 \& \mathrm{dt}=11.8 .2020 .23 .39 .25 .845$. Acesso em: 9 set. 2020.

PARANÁ. Lei n. ${ }^{\circ}$ 20.149, de 17 de março de 2020. Cria o dispositivo Salve Maria, em atenção às mulheres vítimas de violência. Paraná. Disponível em: https://www.legislacao.pr.gov.br/legislacao/pesquisarAto.do?action=exibir\&codAto=232864\&i ndice $=1 \&$ totalRegistros $=1 \& \mathrm{dt}=11.8 .2020 .23 .48 .46 .563$. Acesso em: 9 set. 2020 .

PARANÁ. Lei n. ${ }^{0}$ 20.239, de 10 de junho de 2020. Obriga a disponibilização de produto antisséptico em banheiros de uso coletivo para higienização dos assentos sanitários. Paraná. Disponível em: http://portal.assembleia.pr.leg.br/modules/mod_legislativo_arquivo/mod_ legislativo_arquivo.php?leiCod=52280\&tipo=L\&tplei=0. Acesso em: 9 set. 2020.

PARANÁ. Lei n. ${ }^{\circ}$ 20.189, de 28 de abril de 2020. Obriga, no Estado do Paraná, o uso de máscaras enquanto perdurar o estado de calamidade pública em decorrência da pandemia do coronavírus SARS-CoV-2, e adota outras providências. Paraná. Disponível em: https://www.legislacao.pr.gov.br/legislacao/pesquisarAto.do?action=exibir\&codAto=234172\&i ndice $=1 \&$ totalRegistros $=2 \& \mathrm{dt}=11.8 .2020 .23 .41 .30 .39$. Acesso em: 9 set. 2020 .

PARANÁ. Lei Complementar n. ${ }^{0}$ 221, de 6 de abril de 2020. Transfere os recursos do Fundo Especial de Modernização da Assembleia Legislativa do Paraná, instituído pela Lei Complementar n. ${ }^{\circ}$ 154, de 10 de janeiro de 2013, para o Fundo Estadual de Saúde do Paraná, a fim de viabilizar, prioritariamente, as medidas de enfrentamento à emergência de saúde pública de importância internacional relacionada ao coronavírus SARS-CoV-2. Paraná. Disponível em: https://www.legislacao.pr.gov.br/legislacao/pesquisarAto.do?action=exibir\&codAto=233628\&i ndice $=1 \&$ total Registros $=1 \& \mathrm{dt}=11.8 .2020 .23 .51 .9 .101$. Acesso em: 9 set. 2020 . 
PARANÁ. Resolução n. ${ }^{\circ}$ 11, de 23 de agosto de 2016. Institui o Regimento Interno da Assembleia Legislativa e adota outras providências. Paraná. Disponível em: http://www.assembleia.pr.leg.br/legislacao/regimento-interno. Acesso em: 15 ago. 2020.

PARANÁ. Resolução n. ${ }^{\circ}$, de 23 de março de 2020. Institui o sistema de deliberação remota no âmbito do processo legislativo da Assembleia Legislativa do Paraná, a ser utilizado durante a emergência de saúde pública relacionada ao coronavírus sarscov-2. Paraná. Disponível em: http://portal.assembleia.pr.leg.br/modules/mod_legislativo_arquivo/mod_legislativo_arquivo.ph p?leiCod=52213\&tipo=L\&tplei=1. Acesso em: 15 ago. 2020.

PARANÁ. Projeto de Lei n. ${ }^{\mathbf{0}} \mathbf{4 8 6}$ de 5 de agosto de 2020. Estabelece medidas a serem adotadas no âmbito do sistema de transporte coletivo metropolitano de passageiros da região metropolitana de Curitiba para enfrentamento da emergência de saúde pública decorrente do coronavírus (COVID-19). Paraná. Disponível em: http://portal.assembleia.pr.leg.br/index.php/pesquisalegislativa/proposicao?idProposicao=92993. Acesso em: 15 ago. 2020.

RODRIGUES, Juliana Nunes; AZEVEDO, Daniel Abreu de. Pandemia do Coronavírus e (des)coordenação federativa: evidências de um conflito político-territorial. Espaço e Economia. Revista Brasileira de Geografia Econômica, n. 18, 2020. Disponível em: http://journals.openedition.org/espacoeconomia/12282. Acesso em 6. nov. 2020.

SANTOS, Fabiano Guilherme Mendes. O poder legislativo nos estados: diversidade e convergência. Rio de Janeiro: FGV Editora, 2001.

SCHLEGEL, Rogerio. Presidencialismo e influência restrita no centro limitam poder de assembleias. In: TOMIO, Fabrício Ricardo de Limas; RICCI, Paolo. Governadores e Assembleias Legislativas. Instituições e política nos estados brasileiros. São Paulo: Alameda. 2018. p-253-287.

SOUZA, Celina. Federalismo e gasto social no Brasil: tensões e tendências. Lua Nova: Revista de Cultura e Política, São Paulo, n. 52, p. 5-28, 2001.

TECPAR. Governo do Paraná assina memorando técnico com a Rússia para estudar vacina. Tecpar. Publicado em 12 ago. 2020. Disponível em: http://www.tecpar.br/Noticia/Governo-doParana-assina-memorando-tecnico-com-Russia-para-estudar-vacina. Acesso em: 9 set. 2020.

TAVARES, Diogo; MORAES, Luiz Fernando. O parlamento estadual enquanto ator político: breve análise da relação executivo-legislativo na $17^{\text {a }}$ legislatura da Assembleia Legislativa do Paraná (2011-2014). Revista do Legislativo Paranaense, Curitiba, n. 2, ago. 2018, p. 43-60. Disponível em: http://revista.alep.pr.gov.br/index.php/escolalegislativo/article/view/28. Acesso em: 4 nov. 2020.

TOMIO, Fabricio Ricardo; ORTOLAN, Marcelo Augusto Biehl; DE CAMARGO, Fernando Santos. Análise comparativa dos modelos de repartição de competências legislativas nos estados federados. Revista da Faculdade de Direito UFPR, Curitiba, v. 51, 2010.

TOMIO, Fabrício Ricardo de Limas; RICCI, Paolo. O governo estadual na experiência política brasileira: os desempenhos legislativos das assembleias estaduais. Revista de Sociologia e Política, Curitiba, v. 20, n. 41, p. 193-217, 2012.

TOMIO, Fabrício Ricardo de Limas; RICCI, Paolo. Governadores e Assembleias Legislativas: instituições e política nos estados brasileiros. São Paulo: Alameda Editorial; 2018. 
VIANA, Ana Luiza D'Ávila; LIMA, Luciana Dias de; OLIVEIRA, Roberta Gondim de. Descentralização e federalismo: a política de saúde em novo contexto - lições do caso brasileiro.Ciênc. Saúde coletiva, São Paulo, v. 7, n. 3, p. 493-507, 2002. Disponível em: http://www.scielo.br/scielo.php?script=sci_arttext\&pid=S1413-81232002000300008\&lng=em $\&$ nrm=iso. Acesso em: 6 nov. 2020. 


\section{ANEXO 1}

Mecanismo de busca dos requerimentos de pedidos de informação feitos no período de 11 de março a 31 de agosto de 2020 no sítio eletrônico da Alep: Disponível em:

http://portal.assembleia.pr.leg.br/index.php/pesquisa-legislativa/proposicao.

A Não seguro | portal.assembleia.pr.leg.br/index.php/pesquisa-legislativa/proposicao

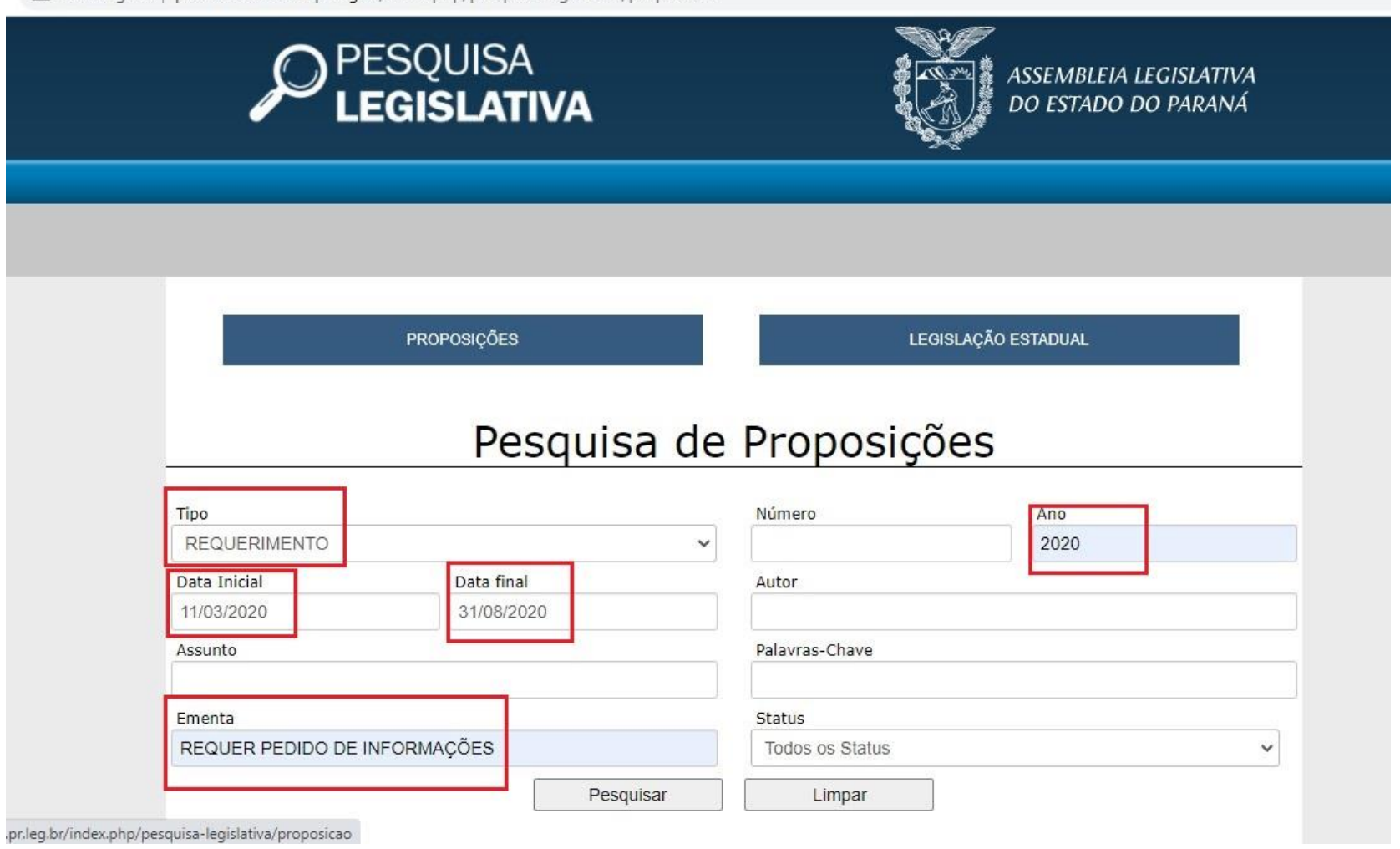

A Não seguro | portal.assembleia.pr.leg.br/index.php/pesquisa-legislativa/proposicao

\section{PESQUISA
LEGISLATIVA}

\section{Pesquisa de Proposições}

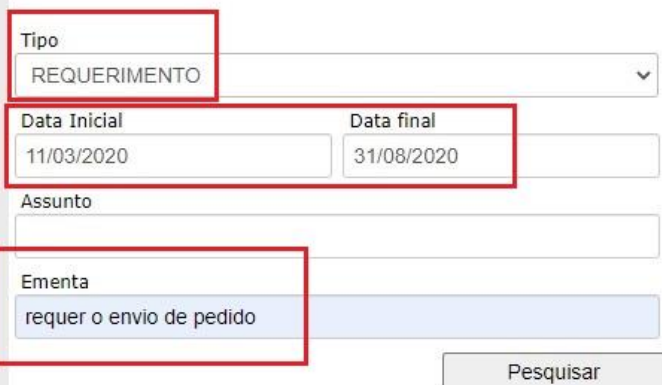

\begin{tabular}{|l|l|}
\hline Número & Ano \\
\hline Autor & 2020 \\
\hline
\end{tabular}

